\title{
The influence of social networks in increasing fruit and vegetables consumption in university students: a randomised controlled study
}

\author{
A.A. Hafiz, A.M. Gallagher and A.J. Hill \\ Nutrition Innovation Centre for Food and Health, Ulster University, Coleraine BT52 1SA, UK.
}

Despite the benefits of fruit and vegetables $(\mathrm{F} \& \mathrm{~V})$ consumption on health, university students face difficulties adapting and/or maintaining a healthy lifestyle when living away from home. Adverse health-related behaviours are prevalent in this population ${ }^{(1-3)}$ which potentially impact on longer-term health beyond young adulthood ${ }^{(4)}$. The present study aimed to 1) increase fruit and vegetable consumption in students living away from home, and 2) to determine whether F\&V consumption was further enhanced when social networks (e.g. Facebook) providing nutritional education was also available.

A total of 60 (36 female 24 male) full-time university students living away from home were recruited and randomly allocated to one of 3 study groups, namely: 'Control' received no intervention, ' $F \& V$ ' received two and three fruits and vegetables respectively for 4 weeks from an individualised preferred list, and the ' $F \& V+E d u c a t i o n$ ' received $F \& V$ (as for the $F \& V$ group) plus nutrition education delivered via Facebook and which focused on benefits of $F \& V$ consumption. Consumption of $F \& V$ was assessed pre-intervention using a validated questionnaire and post intervention using a 4 day semi-quantitative food diaries. Compliance relating to consumption of F\&V provided was assessed using records of waste/uneaten F\&V. Analysis of food diaries was undertaken using Nutritics software and SPSS version 24 used for statistical analysis. All data were log-transformed before statistical analysis using Paired sample t-test and ANOVA.

\begin{tabular}{|c|c|c|c|c|c|c|}
\hline Daily portions of $\mathrm{F} \& \mathrm{~V}$ & Control group $(\mathrm{n}=20)$ & $P$ & F\&Vgroup $(n=20)$ & $P$ & $\mathrm{~F} \& \mathrm{~V}+$ Education group $(\mathrm{n}=20)$ & $P$ \\
\hline \multicolumn{7}{|l|}{ Food-diary ${ }^{1}$} \\
\hline Pre(baseline) & $1.5(0.5)$ & $0 \cdot 287^{\mathrm{a}}$ & $1.7(0.4)$ & $<.0001^{\mathrm{a}}$ & $1.6(0.5)$ & $<.0001^{\mathrm{a}}$ \\
\hline Post(4weeks) & $1.6(0.4)$ & & $3.8(1.1)$ & & $3.7(1.7)$ & \\
\hline$\Delta \mathrm{F} \& \mathrm{~V}^{\mathrm{b}}$ & $0.1(0.5)$ & & $2.2(1.2)$ & & $2 \cdot 2(1.5)$ & $<.0001^{\mathrm{b}}$ \\
\hline \multicolumn{7}{|l|}{ Return bags ${ }^{2}$} \\
\hline Pre(baseline) & NA & & $1.7(0.4)$ & $<.0001^{\mathrm{a}}$ & $1.6(0.5)$ & $<.0001^{\mathrm{a}}$ \\
\hline Post(4weeks) & NA & & $4.6(0.6)$ & & $4.7(0.4)$ & \\
\hline$\Delta \mathrm{F} \& \mathrm{~V}^{\mathrm{c}}$ & NA & & $2.8(0.7)$ & & $3.0(0.6)$ & $0.373^{\mathrm{c}}$ \\
\hline
\end{tabular}

F\&V, Fruit and Vegetable; $\Delta \mathrm{F} \& \mathrm{~V}$, Post minus Pre intake; NA, not applicable. Values are mean (SD) for F\&V portions reported from ${ }^{1}$ food-diary or ${ }^{2}$ return bags. ${ }^{a}$ Pre versus post intervention intake compared using paired Sample t-test. ${ }^{b} \mathrm{Change}$ in $\mathrm{F} \& \mathrm{~V}$ intake compared across groups using ANOVA. ${ }^{\mathrm{c}}$ Change in F\&V intake compared across groups using an independent t-test.

Participants at baseline were mean age 24.4y (SD 3.7) y, BMI 25.4 (SD 4.7) kg/m² and study groups did not differ by age. Consumption of $\mathrm{F} \& \mathrm{~V}$ increased in both intervention groups $(P<.0001)$ from baseline to end of study with food diary data suggesting that $31 \%$ of participants in both intervention groups consumed 5 portions of F\&V each day. However in contrast data from 'return bags' suggested $65 \%$ achieved this in both intervention groups. $70 \%$ of participants engaged with Facebook regularly. In conclusion, this study showed that providing F\&V weekly increased consumption in university students and providing additional nutrition education (via Facebook) did not further enhance intakes of F\&V. Further work is currently underway to assess biomarkers of F\&V intake to objectively assess $\mathrm{F} \& \mathrm{~V}$ intakes during the study period and to determine whether continuing the nutrition education component can help sustain these changes in F\&V intakes.

This work was supported by Ulster University and with financial support from the Royal Embassy of Saudi Arabia

1. Kelly NR, Mazzeo SE, Bean MK (2013) J Nutr Educ Behav 45, 304-313.

2. Bray SR, Kwan MYW (2006) J Am Coll Health 55, 77-82.

3. Strong KA, Parks SL, Anderson E et al. (2008) J Am Diet Assoc 108, 1708-1715.

4. Deliens T, Clarys P, De Bourdeaudhuij I et al. (2014) BMC Public Health 14, 53. 